\title{
ANALISIS KAPASITAS KERJA DAN KEBUTUHAN BAHAN BAKAR TRAKTOR TANGAN BERDASARKAN VARIASI POLA PENGOLAHAN TANAH, KEDALAMAN PEMBAJAKAN DAN KECEPATAN KERJA
}

\author{
The Analysis of Working Capasity and Fuel Consumption of Hand Tractor in Various Tillage Pattern, \\ Plowing Depth and Working Speed
}

Zulias Mardinata, Zulkifli

Fakultas Pertanian, Universitas Islam Riau, Jl. Kaharudin Nasution Km. 11 No. 113 Marpoyan Simpang Tiga, Pekanbaru, Riau 28284

Email: nataugm@yahoo.com

\begin{abstract}
ABSTRAK
Traktor tangan merupakan jenis traktor yang banyak digunakan khususnya dalam pengolahan tanah oleh para petani sebagai usaha untuk meningkatkan produktivitas. Hasil pengolahan tanah dipengaruhi oleh kedalaman pembajakan dan kecepatan kerja traktor, sementara kedalaman pembajakan dan kecepatan kerja berpengaruh terhadap kapasitas kerja dan kebutuhan bahan bakar. Tujuan dari penelitian ini adalah untuk menghitung besarnya kebutuhan bahan bakar dan kapasitas kerja traktor tangan dengan alat pengolah tanah bajak singkal tunggal dengan variasi pola pengolahan tanah, kedalaman pembajakan dan kecepatan kerja. Pola pengolahan yang digunakan adalah pola bolak-balik rapat dan pola berkeliling. Penelitian menggunakan Rancangan Acak Kelompok (RAK) faktorial. Faktor pertama adalah kedalaman bajak singkal yang terdiri dari 3 (tiga) taraf perlakuan yaitu : kedalaman bajak $10 \mathrm{~cm}$ (D1), $15 \mathrm{~cm}$ (D2), dan $20 \mathrm{~cm}$ (D3). Faktor kedua adalah kecepatan traktor terdiri dari 3 (tiga) taraf perlakuan yaitu : kecepatan maju traktor 0,83 $\mathrm{m} / \mathrm{s}$ (V1), 1,25 m/s (V2), dan 1,67 m/s (V3). Adapun parameter diukur adalah konsumsi bahan bakar dan kapasitas kerja traktor tangan untuk masing-masing pola pengolahan tanah. Hasil penelitian diperoleh bahwa pada kedalaman pembajakan 10-20 cm dan kecepatan kerja 0,83-1,67 m/s untuk penyiapan lahan seluas 1 ha dengan pola bolak-balik rapat, kebutuhan bahan bakar rata-rata adalah 2,066 1/jam, pada pola berkeliling adalah 1,107 1/jam, dan dengan interaksi faktor kecepatan dengan kedalaman pembajakan adalah 1,205 - 3,059 1/jam. Kapasitas kerja rata-rata adalah 2,492 jam/ ha, pada pola berkeliling adalah $4,651 \mathrm{jam} / \mathrm{ha}$, dan interaksinya adalah $0,868-1,787 \mathrm{l} / \mathrm{jam}$. Kecepatan dan kedalaman pembajakan berbanding lurus dengan konsumsi bahan bakar dan kapasitas kerja. Pola pengolahan tanah terbaik agar konsumsi bahan bakar efisien dan kapasitas kerja maksimal adalah pola berkeliling.
\end{abstract}

Kata kunci: Konsumsi bahan bakar, kapasitas kerja, kecepatan, kedalaman, pola pengolahan

\begin{abstract}
Hand tractor is a type of tractor that is widely used especially in land cultivation by farmers in an effort to increase productivity. The result of land cultivation is influenced by plowing depth and working speed, meanwhile the plowing depth and working speed influence working capasity and fuel consumption. The aim of this research is to calculate need of fuel consumption and work capasity of hand tractor with single moldboard plow cultivate in various of tillage patterns, plowing depths, working speeds. The tillage patterns used in this research are returned closing and circle methods. This study uses a randomized block design (RBD) factorial. The first factor is the depth of plow consisting of 3 (three) standard treatments, namely: plowing depth $10 \mathrm{~cm}$ (D1), $15 \mathrm{~cm}$ (D2), $20 \mathrm{~cm}$ (D3). The second factor is the speed of the tractor consists of three (3) level of treatment that is: tractor forward speed of $0.83 \mathrm{~m} / \mathrm{s}(\mathrm{V} 1), 1.25 \mathrm{~m} / \mathrm{s}(\mathrm{V} 2)$, and $1,67 \mathrm{~m} / \mathrm{s}$ (V3). The parameters of this research are calculate fuel consumption and work capasity of each method with returned closing and circle method.The result showed that in plowing depth 10-20 cm and working capasity $0,83-1,67 \mathrm{~m} / \mathrm{s}$ for cultivating an area of 1 ha with returned closing method is 2.066 1/hour, while the circle method is around 1,107 1/hour, and the interaction factor of working speed and plowing depth is 1,205-3,059 1/hours. The average of working capasity is 2,492 hours/ha, in circle method is 4,651 hours/ha, and interaction factor of working speed and plowing depth is 0,868-1,787 hours/ha. Working speed and plowing depth are liniear with fuel consumption and working capasity. The best method in order to efficient fuel consumption and maximum working capasity is the circle method.
\end{abstract}

Keywords: Fuel consumption, working capasity, working speed, plowing depth, and tillage pattern 


\section{PENDAHULUAN}

Traktor roda dua sudah lama dikenal oleh petani di Indonesia. Jenis traktor ini semakin banyak digunakan khususnya dalam pengolahan tanah oleh para petani sebagai usaha untuk meningkatkan produktivitas. Hal ini terlihat dengan semakin bertambahnya jumlah traktor di lapangan untuk penyiapan lahan. Data terakhir diketahui bahwa populasi traktor tangan di Indonesia pada tahun 2012 sebanyak 501.433 unit dengan luas lahan 7.890.000 ha (BPS 2013).

Traktor roda dua (two wheel drive tractor) atau traktor tangan (hand tractor) adalah mesin pertanian yang dapat dipergunakan untuk mengolah tanah dan pekerjaan pertanian lainnya. Untuk kegiatan pengolahan tanah, mesin ini mempunyai efisiensi yang tinggi, karena pembalikan dan pemotongan tanah dapat dikerjakan dalam waktu bersamaan (Hardjosentono dkk. 1985).

Bila dilihat dari segi ekonomis, penggunaan traktor roda dua di Indonesia khususnya di Provinsi Riau lebih unggul dan lebih efektif karena lahan pertanian di Riau pada umumnya merupakan lahan kecil dan sempit.

Tujuan pengolahan tanah dengan traktor adalah untuk menciptakan keadaan fisik tanah yang sesuai, untuk pertumbuhan tanaman dengan memanfaatkan peralatan yang bekerja secara mekanis dan berkapasitas besar. Pengolahan tanah pertama (primary tillage) adalah suatu tahap pengolahan tanah dalam mempersiapkan tanah untuk pertanaman dan membersihkan tumbuhan pengganggu, dimana pada tahap ini tanah dipotong, dilonggarkan, dan dibalik. Alat yang digunakan antara lain adalah bajak piring atau bajak singkal (Yunus, 2004).

Pengolahan tanah tidak hanya merupakan kegiatan lapang untuk memproduksi hasil tanaman, tetapi juga berkaitan dengan kegiatan lainnya seperti penyebaran benih (penanaman bibit), pemupukan, perlindungan tanaman, dan panen. Keterkaitan ini sangat erat sehingga tujuan yang ingin dicapai dalam pengolahan tanah tidak terlepas dari keberhasilan dalam kegiatan lainnya. Pengolahan tanah mempengaruhi penyebaran dan penanaman benih. Pengolahan tanah dapat juga dilakukan bersamaan dengan pemupukan serta dianggap pula sebagai suatu metoda pengendalian gulma (IPB, 2010).

Hasil penelitian Rachman (2000) menunjukkan bahwa pada lahan bergambut, penyiapan lahan dengan mengolah tanah menggunakan traktor tangan dapat dilakukan dengan kedalaman olah kurang dari $20 \mathrm{~cm}$ untuk menghindari terkupasnya lapisan pirit. Dibandingkan dengan cara manual, pengolahan tanah dengan traktor tangan dapat menekan kebutuhan waktu kerja dari $142 \mathrm{jam} / \mathrm{ha}$ menjadi $17 \mathrm{jam} / \mathrm{ha}$ dengan hasil padi yang relatif sama.

Pola pengolahan tanah erat hubungannya dengan waktu yang hilang karena belokan selama pengolahan tanah. Pola pengolahan harus dipilih dengan tujuan untuk memperkecil sebanyak mungkin pengangkatan alat untuk mengurangi sebanyak mungkin waktu berbelok karena pada waktu diangkat alat itu tidak bekerja. Oleh karena itu harus diusahakan bajak atau garu tetap bekerja selama waktu operasi di lapangan. Makin banyak pengangkatan alat pada waktu belok, makin rendah efesiensi kerjanya.

Pola pengolahan tanah yang banyak dikenal dan dilakukan adalah pola bolak-balik rapat, pola berkeliling, pola spiral, pola tepi, pola tengah, dan pola alfa. Pola spiral paling banyak digunakan karena pembajakan dilakukan terus menerus tanpa pengangkatan alat (Rizaldi, 2006).

Prayudyanto dkk. (2008), menyatakan bahwa kecepatan kendaraan dan konsumsi BBM mempunyai hubungan yang kuat. Semakin cepat maju traktor maka konsumsi BBM akan semakin meningkat pula. Tingginya kecepatan traktor dikarenakan piston lebih banyak membakar BBM. Semakin banyak BBM yang dibakar maka semakin banyak tenaga yang dihasilkan sehingga semakin cepat kenderaan bergerak.

Tenaga penggerak yang diperlukan untuk mengoperasikan traktor roda dua berasal dari pembakaran solar. Selain dengan menggunakan bahan bakar alternatif untuk meningkatkan kualitas kinerja pada traktor roda dua, maka dapat juga dilakukan dengan pengefesienan penggunaan bahan bakar pada traktor tangan tersebut. Oleh karena itu perlu penelitian untuk mengetahui berapa komsumsi bahan bakar (solar) pada traktor dalam mengolah tanah. Tujuan dari penelitian ini adalah untuk menghitung besarnya kebutuhan bahan bakar dan kapasitas kerja traktor tangan dengan alat pengolah tanah bajak singkal tunggal dengan variasi berbagai kedalaman pembajakan dan kecepatan pengolahan tanah.

\section{METODE PENELITIAN}

Penelitian dilakukan berdasarkan rancangan acak kelompok (RAK) faktorial pada lahan tanah dengan metode bolak-balik rapat dan berkeliling. Pengolahan tanah yang dilakukan meliputi satu kali bajak. Penelitian dilakukan di kebun percobaan Fakultas Pertanian Universitas Islam Riau dari bulan Maret sampai Mei 2013. Penelitian dilakukan dengan menggunakan traktor tangan YANMAR BIMA BM-1 (TF $85 \mathrm{MLY}$ ) dengan alat pengolah tanah bajak singkal tunggal. Ukuran petakan lahan yang dipakai adalah 6 x 18 m.

Faktor pertama adalah kedalaman bajak singkal (D) yang terdiri dari 3 (tiga) taraf perlakuan yaitu : kedalaman bajak 10 $\mathrm{cm}$ (D1), $15 \mathrm{~cm}$ (D2), dan $20 \mathrm{~cm}$ (D3). Faktor kedua adalah kecepatan traktor (V) terdiri dari 3 (tiga) taraf perlakuan yaitu : $0,83 \mathrm{~m} / \mathrm{s}(\mathrm{V} 1), 1,25 \mathrm{~m} / \mathrm{s}$ (V2) dan $1,67 \mathrm{~m} / \mathrm{s}(\mathrm{V} 3)$.

Prosedur penelitian : Sebelum mesin traktor dihidupkan, tangki bahan bakar traktor diisi sampai penuh sebelum traktor dijalankan, setelah itu mengolah lahan dengan kecepatan $0,83 \mathrm{~m} / \mathrm{s}, 1,25 \mathrm{~m} / \mathrm{s}, 1,67 \mathrm{~m} / \mathrm{s}$ dan kedalaman bajak 10 
$\mathrm{cm}, 15 \mathrm{~cm}$ dan $20 \mathrm{~cm}$. Setelah selesai mengolah satu petakan, operator mematikan mesin, kemudian mengisi bahan bakar ke dalam tangki sampai penuh dan mencatat volume penambahan bahan bakar yang dimasukkan ke dalam tangki. Hal ini dilakukan dengan 3 kali pengulangan untuk masing-masing perlakuan dan pola pengolahan tanah.

Parameter Penelitian ini adalah:

Komsumsi Bahan Bakar $=\frac{\text { Volume penambahan }}{\text { waktu kerja }}(l / j a m$......(1)

Kapasitas Kerja $=\frac{\text { Waktu Kerja }}{\text { Luas }}(j a m / h a$

Kapasitas Kerja Aktual traktor untuk pegolahan tanah :

$$
K K_{a}=\frac{A}{T}
$$

$$
\begin{aligned}
\mathrm{KK}_{\mathrm{a}} & =\text { Kapasitas kerja aktual } \\
\mathrm{A} & =\text { Total luas aktual } \\
\mathrm{T} & =\text { Total waktu }
\end{aligned}
$$

(Ha/Jam)

(Jam)

Data yang diperoleh selama penelitian dimasukkan ke dalam tabel sesuai parameter penelitian. Selanjutnya dilakukan analisis sidik ragam (anova) dengan menggunakan program SAS. Jika pada hasil sidik ragam (Uji F) terdapat perlakuan yang berpengaruh nyata terhadap parameter yang diamati maka dilanjutkan dengan Uji Beda Nyata Jujur (BNJ) pada taraf 5\%.

\section{HASIL DAN PEMBAHASAN}

Tabel 1. Data pengamatan hasil penelitian dengan pola bolak balik rapat dan pola berkeliling

\begin{tabular}{lccccc}
\hline Perlakuan & & \multicolumn{4}{c}{ Parameter } \\
\hline \multirow{3}{*}{ Kedalaman } & Kecepatan & Kola bolak balik rapat & \multicolumn{2}{c}{ Pola berkeliling } \\
& & KBM & KK $_{\text {aktual }}$ & KBBM & KK $_{\text {aktual }}$ \\
& & (Lam) & $($ Jam/Ha) & $(\mathrm{L} / \mathrm{Jam})$ & $(\mathrm{Jam} / \mathrm{Ha})$ \\
\hline \multirow{3}{*}{$10 \mathrm{~cm}$} & $0,83 \mathrm{~m} / \mathrm{s}$ & 1,205 & 3,052 & 0,868 & 4,693 \\
& $1,25 \mathrm{~m} / \mathrm{s}$ & 1,790 & 3,542 & 0,977 & 5,351 \\
& $1,67 \mathrm{~m} / \mathrm{s}$ & 1,888 & 3,768 & 1,034 & 6,013 \\
\hline \multirow{3}{*}{$15 \mathrm{~cm}$} & $0,83 \mathrm{~m} / \mathrm{s}$ & 1,246 & 1,160 & 0,910 & 2,538 \\
& $1,25 \mathrm{~m} / \mathrm{s}$ & 1,998 & 2,078 & 0,964 & 4,475 \\
& $1,67 \mathrm{~m} / \mathrm{s}$ & 2,045 & 3,564 & 1,126 & 7,742 \\
\hline \multirow{2}{*}{$20 \mathrm{~cm}$} & $0,83 \mathrm{~m} / \mathrm{s}$ & 2,386 & 1,135 & 0,901 & 2,660 \\
& $1,25 \mathrm{~m} / \mathrm{s}$ & 2,973 & 1,737 & 1,394 & 3,336 \\
& $1,67 \mathrm{~m} / \mathrm{s}$ & 3,059 & 2,392 & 1,787 & 5,054 \\
\hline
\end{tabular}

Dari Tabel 1 dapat dilihat bahwa konsumsi bahan bakar tertinggi pada tiap kedalaman pembajakan diperoleh pada kecepatan maju $1,67 \mathrm{~m} / \mathrm{s}$, terendah pada kecepatan $0,83 \mathrm{~m} / \mathrm{s}$ dan kapasitas kerja tertinggi pada tiap kedalaman pembajakan diperoleh pada $\mathrm{V} 3$ atau kecepatan $1,67 \mathrm{~m} / \mathrm{s}$, terendah pada V1 atau kecepatan maju $0,83 \mathrm{~m} / \mathrm{s}$.

Dalam penggunaan traktor, faktor konsumsi bahan bakar dan kapasitas kerja merupakan faktor utama yang dilihat dalam pemilihan traktor. Traktor yang konsumsi bahan bakarnya kecil untuk jarak tempuh yang sama merupakan pilihan yang ingin dicapai. Sementara untuk kapasitas kerja, traktor dengan kapasitas kerja terbesar yang menjadi pilihan. Dari hasil penelitian ini terlihat bahwa konsumsi bahan bakar pada pola berkeliling lebih kecil daripada konsumsi bahan bakar pola bolak balik rapat. Sedangkan untuk parameter kapasitas kerja tampak pola berkeliling lebih besar daripada pola bolak balik rapat.

Dari hasil juga terlihat bahwa semakin dalam pembajakan, maka semakin besar konsumsi bahan bakar dan kapasitas kerjanya. Begitu juga untuk faktor kecepatan traktor, semakin kencang traktor, semakin tinggi pula kapasitas kerjanya.

\begin{tabular}{|c|c|c|c|c|c|}
\hline \multirow{2}{*}{$\begin{array}{c}\text { Pola } \\
\text { pengolahan } \\
\text { tanah }\end{array}$} & \multirow{2}{*}{$\begin{array}{c}\text { Faktor } \\
\text { kedalaman (D) }\end{array}$} & \multicolumn{3}{|c|}{ Faktor kecepatan (V) } & \multirow{2}{*}{ Rerata } \\
\hline & & $0,83 \mathrm{~m} / \mathrm{s}$ & $1,25 \mathrm{~m} / \mathrm{s}$ & $1,67 \mathrm{~m} / \mathrm{s}$ & \\
\hline \multirow{4}{*}{$\begin{array}{c}\text { Bolak balik } \\
\text { rapat }\end{array}$} & $10 \mathrm{~cm}$ & 1.205 & 1.790 & 1.888 & $1.628 \mathrm{~b}$ \\
\hline & $15 \mathrm{~cm}$ & 1.246 & 1.998 & 2.045 & $1.763 \mathrm{~b}$ \\
\hline & $20 \mathrm{~cm}$ & 2.386 & 2.973 & 3.059 & $2.806 \mathrm{a}$ \\
\hline & Rerata & $1.612 b$ & $2.253 \mathrm{a}$ & $2.331 \mathrm{a}$ & 2.066 \\
\hline \multirow{4}{*}{ Berkeliling } & $10 \mathrm{~cm}$ & $0.868 \mathrm{c}$ & $0.977 \mathrm{c}$ & $1.034 \mathrm{c}$ & $0.960 \mathrm{~b}$ \\
\hline & $15 \mathrm{~cm}$ & $0.910 \mathrm{c}$ & $0.964 \mathrm{c}$ & $1.126 b c$ & $1.000 \mathrm{~b}$ \\
\hline & $20 \mathrm{~cm}$ & $0.901 \mathrm{c}$ & $1.394 b$ & $1.787 \mathrm{a}$ & $1.361 \mathrm{a}$ \\
\hline & Rerata & $0.893 \mathrm{c}$ & $1.112 b$ & $1.316 \mathrm{a}$ & 1.107 \\
\hline
\end{tabular}

\section{Konsumsi Bahan Bakar Minyak (L/Jam)}

Tabel 2. Hasil analisis rerata konsumsi bahan bakar minyak (L/Jam)

Keterangan: Angka-angka yang diikuti oleh huruf kecil yang sama tidak berbeda nyata berdasarkan Uji BNJ taraf 5\%.

Konsumsi bahan bakar tertinggi diperoleh pada kecepatan traktor $1,67 \mathrm{~m} / \mathrm{s}$ (V3) dengan rata-rata konsumsi bahan bakar 2,331 L/jam. Konsumsi bahan bakar tertinggi kedua diperoleh pada kecepatan traktor 1,25 m/s (V2) dengan rata-rata konsumsi bahan bakar 2,253 L/Jam, dan konsumsi bahan bakar terendah diperoleh pada kecepatan traktor 0,83 $\mathrm{m} / \mathrm{s}$ (V1) dengan rata-rata konsumsi bahan bakar 1,612 L/jam.

Pada penelitian ini konsumsi bahan bakar semakin besar saat kedalaman pembajakan tanah semakin dalam, dengan kecepatan maju traktor semakin besar pula. Menurut Pramuhadi (2004) penambahan tenaga traktor memerlukan pembakaran yang lebih besar sehingga konsumsi bahan bakar traktor semakin besar selain itu tahanan penetrasi tanah juga mempengaruhi konsumsi bahan bakar traktor.

Konsumsi bahan bakar tertinggi diperoleh pada kedalaman pembajakan $20 \mathrm{~cm}$ (D3) dengan rata-rata konsumsi bahan bakar 2,8061/jam. Konsumsi bahan bakar tertinggikedua diperoleh pada kedalaman pembajakan $15 \mathrm{~cm}$ (D2) dengan rata-rata konsumsi bahan bakar 1,763 1/jam, dan konsumsi bahan bakar terrendah diperoleh pada kedalaman pembajakan $10 \mathrm{~cm}$ (D1) dengan rata-rata konsumsi bahan bakar 1,628 1/ jam. Konsumsi bahan bakar traktor akan semakin besar jika tahanan penetrasi tanah semakin besar pula. Dalam penelitian ini tahanan penetrasi tanah akan semakin besar jika kedalaman olah tanah semakin dalam. Semakin dalam pembajakan maka 
akan semakin lambat traktor berjalan karena tenaga traktor yang diperlukan akan semakin besar. Akibatnya semakin besar pula tenaga yang dibutuhkan untuk menggerakkan traktor. Tenaga traktor dihasilkan dari perputaran torak dalam silinder. Semakin banyak putaran torak di silinder, maka akan semakin banyak menghabiskan bahan bakar.

Pada pola bolak balik rapat, untuk kecepatan traktor $0,83 \mathrm{~m} / \mathrm{s}$, diperoleh rata-rata konsumsi bahan bakar sebesar $1,612 \mathrm{l} / \mathrm{jam}$, untuk kecepatan traktor $1,25 \mathrm{~m} / \mathrm{s}$, diperoleh ratarata konsumsi bahan bakar 2,253 1/jam dan untuk kecepatan traktor $1,67 \mathrm{~m} / \mathrm{s}$, diperoleh rata-rata konsumsi bahan bakar 2,331 1/jam. Pada pola berkeliling, untuk kecepatan traktor $0,83 \mathrm{~m} / \mathrm{s}$, diperoleh rata-rata konsumsi bahan bakar sebesar $0,893 \mathrm{l} / \mathrm{jam}$, untuk kecepatan traktor $1,25 \mathrm{~m} / \mathrm{s}$, diperoleh ratarata konsumsi bahan bakar 1,112 1/jam dan untuk kecepatan traktor $1,67 \mathrm{~m} / \mathrm{s}$, diperoleh rata-rata konsumsi bahan bakar 1,316 1/jam. Dari hasil ini terlihat bahwa semakin tinggi kecepatan traktor maka semakin besar konsumsi bahan bakar. Semakin panjang jarak tempuh traktor tangan maka akan semakin besar tenaga traktor yang dibutuhkan, sehingga konsumsi BBM akan semakin besar pula. Hasilnya konsumsi BBM pola Bolak-Balik Rapat akan lebih besar dibandingkan konsumsi BBM pola berkeliling.

\section{Kapasitas Kerja (Jam/Ha)}

Tabel 3. Hasil analisis rerata kapasitas kerja (Ha/Jam)

\begin{tabular}{|c|c|c|c|c|c|}
\hline \multirow{2}{*}{$\begin{array}{c}\text { Pola } \\
\text { pengolahan } \\
\text { tanah } \\
\end{array}$} & \multirow{2}{*}{$\begin{array}{c}\text { Faktor } \\
\text { kedalaman (D) }\end{array}$} & \multicolumn{3}{|c|}{ Faktor kecepatan (V) } & \multirow{2}{*}{ Rerata } \\
\hline & & $0,83 \mathrm{~m} / \mathrm{s}$ & $1,25 \mathrm{~m} / \mathrm{s}$ & $1,67 \mathrm{~m} / \mathrm{s}$ & \\
\hline \multirow{4}{*}{$\begin{array}{l}\text { Bolak balik } \\
\text { rapat }\end{array}$} & $10 \mathrm{~cm}$ & $3.052 \mathrm{c}$ & $3.542 b$ & $3.768 \mathrm{a}$ & $3.454 \mathrm{a}$ \\
\hline & $15 \mathrm{~cm}$ & $1.160 \mathrm{~g}$ & $2.078 \mathrm{e}$ & $3.564 b$ & $2.267 \mathrm{~b}$ \\
\hline & $20 \mathrm{~cm}$ & $1.135 \mathrm{~g}$ & $1.737 \mathrm{f}$ & $2.392 \mathrm{~d}$ & $1.754 \mathrm{c}$ \\
\hline & Rerata & $1.782 \mathrm{c}$ & $2.452 \mathrm{~b}$ & $3.241 \mathrm{a}$ & 2.492 \\
\hline \multirow{4}{*}{ Berkeliling } & $10 \mathrm{~cm}$ & $4.693 \mathrm{~cd}$ & $5.351 \mathrm{bc}$ & $6.013 b$ & $5.353 \mathrm{a}$ \\
\hline & $15 \mathrm{~cm}$ & $2.538 \mathrm{e}$ & $4.475 d$ & $7.742 \mathrm{a}$ & $4.918 \mathrm{a}$ \\
\hline & $20 \mathrm{~cm}$ & $2.660 \mathrm{e}$ & $3.336 \mathrm{e}$ & $5.054 \mathrm{~cd}$ & $3.683 b$ \\
\hline & Rerata & $3.297 \mathrm{c}$ & $4.387 \mathrm{~b}$ & $6.270 \mathrm{a}$ & 4.651 \\
\hline
\end{tabular}

Keterangan: Angka-angka yang diikuti oleh huruf kecil yang sama tidak berbeda nyata berdasarkan Uji BNJ taraf 5\%.

Dari hasil uji anova (Tabel 3), menunjukkan bahwa perlakuan kecepatan pembajakan memberikan pengaruh sangat nyata. Pada penelitian ini kapasitas kerja semakin tinggi saat kecepatan semakin besar.

Menyatakan Rizaldi (2006), kapasitas kerja suatu alat pengolahan tanah dipengaruhi oleh berberapa faktor, yaitu : 1) Ukuran dan bentuk petakan; 2) Topografi wilayah; 3) Keadaan traktor; 4) Keadaan vegetasi di permukaan tanah; 5) Keadaan tanah; 6) Tingkat keterampilan operator; dan 7) Pola pengolahan tanah. Dari ketujuh faktor tersebut, pola pengolahan tanah merupakan faktor yang paling berpengaruh pada penelitian ini.
Pola pengolahan tanah akan mempengaruhi kapasitas kerja alat pengolah tanah yang digunakan. Pola pengolahan tanah yang baik adalah pola pengolahan tanah yang meminimalisir waktu terbuang. Dalam hal ini, waktu berbelok merupakan waktu yang merugikan bagi kita. Jadi pola pengolahan tanah yang baik adalah pola dengan jumlah berbelok yang paling sedikit.

Untuk luas petakan yang sama, pada pola bolak balik jumlah belokannya lebih banyak dibanding dengan jumlah belokan pada pola berkeliling. Pada pola bolak balik jumlah belokan sekitar 28 kali belokan dan pada pola berkeliling sekitar 22 kali belokan tanpa ada pengangkatan alat bajak karena traktor tangan.

Kapasitas kerja tertinggi diperoleh pada kecepatan traktor 1,67 m/s (V3) dengan rata-rata kapasitas kerja 3,241 Jam/Ha, dan kapasitas kerja terendah diperoleh pada kecepatan traktor $0,83 \mathrm{~m} / \mathrm{s}$ (V1) dengan rata-rata kapasitas kerja 1,782 Jam/Ha. Kapasitas kerja tertinggi diperoleh pada kedalaman pembajakan $10 \mathrm{~cm}$ (D1) dengan rata-rata kapasitas kerja 3,454 Jam/Ha, dan kapasitas kerja terrendah diperoleh pada kedalaman pembajakan $20 \mathrm{~cm}$ (D3) dengan rata-rata kapasitas kerja 1,754 Jam/Ha.

Menurut Yunus (2004) jika kecepatan semakin besar maka kapasitas kerja pun akan semakin besar. Dari Tabel 3 menunjukkan bahwa perlakuan kecepatan dan perlakuan kedalaman pembajakan memberikan pengaruh sangat nyata. Pada penelitian ini kapasitas kerja semakin tinggi saat kecepatan semakin besar. Kapasitas kerja tertinggi diperoleh pada perlakuan kedalaman $10 \mathrm{~cm}$ dengan kecepatan $1,67 \mathrm{~m} / \mathrm{s}$ yaitu 3,768 Jam/Ha dan terendah diperoleh pada perlakuan kedalaman $20 \mathrm{~cm}$ dengan kecepatan $0,83 \mathrm{~m} / \mathrm{s}$ yaitu 1,135 $\mathrm{Jam} / \mathrm{Ha}$.

Hal tersebut sesuai dengan pendapat Yuswar (2004), mengatakan bahwa kecepatan maju merupakan salah satu metode untuk meningkatkan kapasitas kerja alat pertanian yaitu dengan menambah kecepatan maju berarti meningkatkan kapasitas kerja alat pengolah tanah tanpa harus menambah berat dan jumlah unit tenaga penggerak yang membebani tanah.

Semakin panjang jarak tempuh traktor tangan maka akan semakin besar tenaga traktor yang dibutuhkan, sehingga kapasitas kerja akan semakin besar pula. Hasilnya kapasitas kerja pola bolak-balik rapat akan lebih besar dibandingkan kapasitas kerja pola berkeliling. Tenaga traktor traktor yang dikeluarkan dalam penyiapan lahan pertanian menggunakan pola bolak-balik rapat akan lebih besar dibandingkan dengan tenaga traktor yang dikeluarkan dalam penyiapan lahan dengan pola berkeliling. Berdasar hasil analisis: pola berkeliling lebih direkomendasikan.

Nilai kapasitas kerja pola berkeliling rata-rata dua kali lipat nilai kapasitas kerja pola bolak-balik rapat. Kapasitas kerja merupakan perbandingan antara waktu dalam mengolah 
tanah dengan luas lahan yang diolah. Pada pengolahan lahan dengan pola berkeliling, waktu yang terbuang atau waktu yang merugikan lebih kecil daripada waktu yang terbuang pada pola bolak-balik rapat. Hal ini terlihat dari jumlah belokan pada pola bolak balik rapat lebih besar daripada jumlah belokan pada pola berkeliling. Saat berbelok dibutuhkan waktu \pm 2 detik. Itu artinya waktu berbelok pada pola bolak balik rapat adalah 2 detik x 28 belokan $=56$ detik, sedangkan pada pola berkeliling adalah 2 detik x 22 belokan $=44$ detik. Terdapat selisih 12 detik waktu yang dibutuhkan untuk berbelok. Akibatnya waktu efektif pola berkeliling lebih besar daripada waktu efektif pola bolak-balik rapat.

Hal tersebut sesuai dengan pernyataan Suastawa dkk (2000), pola pengolahan tanah erat hubungannya dengan waktu yang hilang karena belokan selama pengolahan tanah. Pola pengolahan harus dipilih dengan tujuan untuk memperkecil sebanyak mungkin pengangkatan alat, karena pada waktu diangkat alat itu tidak bekerja, makin banyak pengangkatan alat pada waktu belok, makin rendah efisiensi kerjanya.

Dari hasil penelitian di atas menunjukkan bahwa uji berbagai kecepatan dengan dua macam pola pengolahan tanah pada masing-masing kedalaman pembajakan memberikan pengaruh terhadap konsumsi bahan bakar dan kapasitas kerja traktor saat pengolahan tanah.

\section{KESIMPULAN DAN SARAN}

\section{Kesimpulan}

1. Kebutuhan bahan bakar rata-rata pada kedalaman pembajakan 10-20 cm dan kecepatan kerja 0,83$1,67 \mathrm{~m} / \mathrm{s}$ untuk penyiapan lahan seluas 1 ha dengan pola bolak-balik rapat adalah 2,066 1/jam, pada pola berkeliling adalah 1,107 1/jam, dan dengan interaksi faktor kecepatan dengan kedalaman pembajakan adalah 1,205 - 3,059 1/jam.

2. Kapasitas kerja rata-rata pada kedalaman pembajakan 10$20 \mathrm{~cm}$ dan kecepatan kerja 0,83-1,67 m/s untuk penyiapan lahan seluas 1 ha dengan pola bolak-balik rapat adalah 2,492 jam/ha, pada pola berkeliling adalah 4,651 jam/ha, dan dengan interaksi faktor kecepatan dengan kedalaman pembajakan adalah $0,868-1,787$ l/jam.

3. Pola pengolahan tanah terbaik agar konsumsi BBM efisien dan kapasitas kerja maksimal adalah pola berkeliling.

\section{Saran}

Dalam penyiapan lahan dan mengolah tanah dengan traktor tangan pada lahan yang sempit seperti lahan yang ada di Provinsi Riau sebaiknya menggunakan pola berkeliling dengan kecepatan traktor $1,67 \mathrm{~m} / \mathrm{s}$ dengan kedalaman pembajakan 10-20 cm.

\section{DAFTAR PUSTAKA}

Badan Pusat Statistik (2013). Populasi traktor tangan Indonesia www.bps.go.id .[5 November 2013].

Center for Data on Information on Energy and Mineral Resources (2009). Handbook of Energy and Economic Statistic of Indonesia 2009, center for data on information on energy and mineral resources, Ministry Energy and Mineral Resources, Jakarta.

Djoyowasito, G. (2002). Pengaruh Kecepatan Maju Bajak terhadap beberapa Sifat Dinamik Tanah dalam Pengolahan Tanah. Tesis. Fakultas Teknologi Pertanian. Institut Pertanian Bogor, Bogor.

Hardjosentono, Wajito, M., Rachlan, E., Badra, I.W. dan Tarmana, R.D. (1985). Mesin- Mesin Pertanian. Bumi Aksara, Jakarta.

Hendriadi, A., Sulistiadji, K. dan Prabowo, A. (2002). Analisis sistem dalam pengembangan alsintan pengolahan berbagai jenis tanah. http://mekanisasi.litbang.deptan. go.id/abstrak/th-2000/alsin-pengolahan_tanah.htm. [17 April 2013].

Institut Pertanian Bogor (2010). Alat dan mesin pengolah tanah. http://web.ipb.ac.id/ tepfteta/elearning/media/ Teknik\%20Mesin\%20Buditenagatrakto\%20Pertanian/ Alat\%20Pengolahan\%20tanah/index4april.html. . .]17 April 2013].

Prayudyanto, M.M., Jacub, C., Driejana, R. dan Tamin, O.Z. (2008). Background for optimization of fuel consumtion at congested network using hydrodynamic traffic theory. Proceeding Forum Studi Transportasi antar Perguruan Tinggi International Symposium. Jember.

Pramuhadi, G. (2004). Studi Hubungan Antara Beban Mesin Traktor dan Efisiensi Pengolahan Tanah. Tesis. Program Studi Ilmu Keteknikan Pertanian. Institut Pertanian Bogor, Bogor.

Rachman, A. (2000). Penyiapan lahan. http://balitra.net/ berita/menu.php .[17 April 2013].

Rizaldi, T. (2006). Mesin Peralatan. Departemen Teknologi Pertanian Universitas Sumatera Utara, Medan.

Suastawa, I.N., Hermawan, W. dan Sembiring, E.N. (2000). Konstruksi dan Pengukuran Kinerja Traktor Pertanian. Laporan Penelitian. Teknik Pertanian. Fakultas Teknologi Pertanian. Institut Pertanian Bogor, Bogor.

Yunus, Y. (2004). Tanah dan Pengolahannya. Alphabeta, Bandung.

Yuswar, Y. (2004). Perubahan beberapa Sifat Fisik Tanah dan Kapasitas Kerja Traktor Akibat Lintasan Bajak Singkal pada Berbagai Kadar Air Tanah. Tesis. Program Pascasarjana Universitas Syiah Kuala, Banda Aceh. 